\title{
Schizosaccharomyces isolation method
}

\author{
Santiago Benito, Felipe Palomero, Fernando Calderón, Antonio Morata, and José Antonio Suárez-Lepe \\ Departamento Química y Tecnología de Alimentos, Universidad Politécnica de Madrid, Ciudad Universitaria S/N, 28040 \\ Madrid, Spain
}

\begin{abstract}
Summary This study discusses the optimization of a selective and differential medium which would facilitate the isolation of Schizosaccharomyces (a genus with a low incidence compared to other microorganisms) to select individuals from this genus for industrial purposes, especially in light of the recent recommendation of the use of yeasts from this genus in the wine industry by the International Organisation of Vine and Wine, or to detect the presence of such yeasts, for those many authors who consider them food spoilers. To this end, we studied various selective differential agents based on the main physiological characteristics of these species, such as their high resistances to high concentrations of sugar, sulfur dioxide, sorbic acid, benzoic acid, acetic acid or malo ethanolic fermentation. This selective medium is based on the genus resistance to the antibiotic actidione and its high resistance to inhibitory agents such as benzoic acid. Malic acid was used as a differential factor due to the ability of this genus to metabolise it to ethanol, which allows detecting of the degradation of this compound. Lastly, the medium was successfully used to isolate strains of Schizosaccharomyces pombe from honey and honeycombs.
\end{abstract}

\section{Introduction}

Genus Schizosaccharomyces have occasionally been described as spoilage, usually due to the production of negative sensory characteristics [1]. However, it also has been used for industrial purposes, particularly in the wine industry, due to their deacidifying properties which they owe to their ability to metabolise L-malic acid to ethanol $[1,2]$. On the other hand, during the last years new uses of this genus has been developed [1-3]. One of this it is application in ageing over lees, due to their polysaccharide release superiority. The literature also describes the use of certain Schizosaccharomyces mutants to reduce the initial content of gluconic acid in spoiled grape musts. S. pombe Fermentation also provides a way of increasing the overall pyranoanthocyanin content of red wines, and of stabilising their colour during ageing [3]. The International Organisation of Vine and Wine (OENO/MICRO/97/75/Stage 7) recommends "Deacidification by Schizosaccharomyces" practice. However, the number of commercial strains is very limited, probably due to the low incidence of this genus compared to other microorganisms [4,5]. Efforts should therefore focus on the isolation and selection of specimens from this species for industrial applications.

There are just a few references in the literature which discuss the isolation of Schizosaccharomyces genus in grapes [5]. Most of isolation references however refer to products with a high sugar content, such as concentrate musts, honey, sweets, molasses or dried fruit [5]. So it would therefore seems more logical to try and find these microorganisms in those niches.

These yeasts are capable of growth on media containing high concentrations of sugar such as Malt Yeast $50 \%$ Glucose Agar and at temperatures of $37^{\circ} \mathrm{C}$
[5]. They also have been described as highly resistant to antimicrobial agents such as benzoic acid or sorbic acid [5]. This yeast also below to one of the few genus described as actidione resistant [5]. Lastly, it should be mentioned that one of the main characteristics of this species is its ability to carry out maloalcoholic fermentation and achieving malic deacidification of about 75 to $100 \%$, depending on the strain and culture medium. Such degradation in a culture medium would be indicative of the presence of yeasts with this ability.

This study applies the principles outlined above to optimise a selective medium which would facilitate the isolation of Schizosaccharomyces yeasts compared to existing, traditional media, thus counterbalancing the drawbacks of their reduced presence.

\section{Material and methods}

Several solid culture media were used in this study. The following selective agents were used: antibiotic actidione, sorbic acid and benzoic acid. Malic acid was used as differential factor. Yeast strains indicative of the effectiveness of the growth media were taken from type culture of Universidad Politécnica de Madrid.

Finally some of these media were tested in supermarket honey, eco-friendly bee farms honey and honeycombs.

\section{Results and discussion}

\subsection{Growth results obtained in culture media enriched with differential-selective agents}

After culturing all of the studied strains in YEPD medium enriched in actidione, the only strains which were able 
Table 1. Growth results in Petri dishes after 10 days in culture.

\begin{tabular}{|c|c|c|c|c|c|}
\hline Specie & YEPD & $\begin{array}{c}\text { YEPD } \\
\mathrm{Bz}\end{array}$ & $\begin{array}{c}\text { YEPD } \\
\text { Sb }\end{array}$ & $\begin{array}{c}\text { YEPD } \\
\text { Act }\end{array}$ & $\begin{array}{c}\text { YEPD } \\
\mathrm{BzCl}\end{array}$ \\
\hline $\begin{array}{c}\text { D. } \\
\text { bruxellensis }\end{array}$ & + & - & + & + & - \\
\hline D. anomala & + & - & + & + & - \\
\hline S. pombe & + & + & - & + & + \\
\hline $\begin{array}{c}\text { P. } \\
\text { guilliermondii }\end{array}$ & + & - & - & + & - \\
\hline H. uvarum & + & - & - & + & - \\
\hline $\begin{array}{c}\text { C. } \\
\text { parapsilosis }\end{array}$ & + & - & - & $+/-$ & - \\
\hline S. ludwigii & + & + & - & - & - \\
\hline Z. bailii & + & + & + & - & - \\
\hline Subsubsección & & & & & \\
\hline
\end{tabular}

+ , Positive growth; -, absence of yeast growth; + /-, peak growth; in media including varying concentrations of a selective agent: Bz(Benzoate), Sb (Sorbate), Act (Actidione) and $\mathrm{Cl}$ (Cloramphenicol).

to developed were $S$. pombe, D. bruxellensis, Dekkera anomala, Kloeckera apiculata, Hanseniaspora uvarum, Pichia guilliermondii, and some Candida parapsilosis specific strains (Table 1). No growth whatsoever was detected for any of the other strains tested under these conditions, which validates the use of actidione as the main effective selective agent to isolate yeasts belonging to the genus Schizosaccharomyces.

All of the strains studied which tested resistant to the antibiotic actidione were cultured in the rest of the media enriched with additional differential-selective agents and yielded the results shown in Table 1. The study of these strains was supplemented with that of the species Saccharomycodes ludwigii and Zygosaccharomyces bailii, due to their high incidence in niches similar to those ascribed to Schizosaccharomyces and their high level of resistance to the above-named additives. Both species proved resistant to secondary selective agents at the highest concentrations used, but were inhibited in the media containing actidione (Table 1). The medium enriched with potassium sorbate at different concentrations inhibited the growth of the strains of $S$. pombe studied at the concentration of $400 \mathrm{mg} / \mathrm{L}$ at $\mathrm{pH} 3.5$, although other authors have reported resistance at up $600 \mathrm{mg} / \mathrm{L}$ [5]. According to this study, it does not seem worth including this selective agent in the formulation of differential-selective media used for Schizosaccharomyces, as other actidione resistant yeasts such as the strains of D. bruxellensis and D. anomala studied grew even at the maximum concentration used, that is $600 \mathrm{mg} / \mathrm{L}$; in addition, according to some authors, these exhibit resistance at concentrations of up to $1000 \mathrm{mg} / \mathrm{L}$. Further, the actidione-resistant strains of $C$. parapsilosis studied also resisted the maximum concentration used, although it should be noted that other authors have reported sorbate resistance at up to 10 to $20 \mathrm{~g} / \mathrm{L}$ [5]. The sodium benzoate enriched medium inhibited all actidione resistant yeast strains studied to concentrations of $300 \mathrm{mg} / \mathrm{L}$, except for $S$. pombe which resisted the maximum concentration tested that is $600 \mathrm{mg} / \mathrm{L}$. A combained selective medium composed of actidione, potassium benzoate

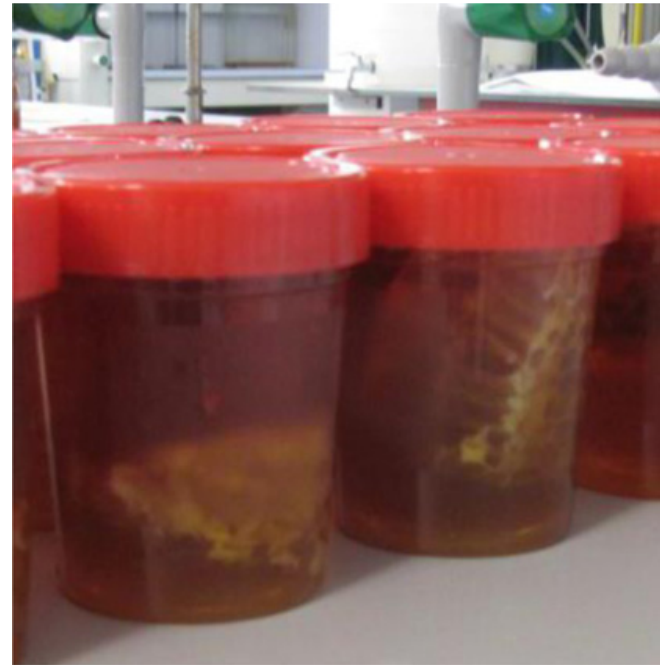

Figure 1. Honeycombs samples immersed in YEPDAcBzClMa medium in sterile $50 \mathrm{~mL}$ containers.

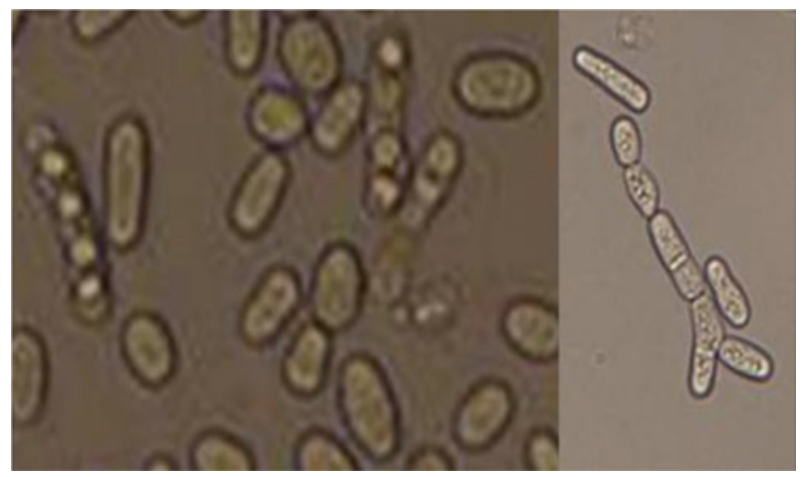

Figure 2. Detail of fission reproduction and sporulation of strains from the isolated cultures.

and cloramphenicol inhibited all actidione resistant strains tested, as well as Saccharomycodes ludwigii and Zygosaccharomyces bailii, although seven days were required for growth.

After observing these results, it appears that for the strain used in this study, the most accurate selective agent after actidione is sodium benzoate, although some other agents such as acetic acid or high concentrations of glucose could probably be added to prevent the emergence of resistant strains [5].

\subsection{Isolation from honey and honeycomb: Classification of yeasts}

It is worth pointing out that the incidence of microorganisms was insignificant in honeys bought from supermarkets and higher in organic honeys and honeycombs (Fig. 1). Microorganisms capable of degrading malic acid were detected in some samples (Fig. 1). The results of the classification of these strains are showed that all of these strains belong to the species $S$. pombe, which has been described as the most common of this genus to be found in food. Figure 2 shows photographed observations of fission reproduction sporulation and four-spore ascus formation observed in the studied isolations. 


\section{Conclusions}

There is a need to detect, isolate and select strains belonging to the genus Schizosaccharomyces due to their interest in relation to modern industrial applications. However, there is a current shortage of specific techniques for their adequate isolation, coupled with the low incidence of these microorganisms, so that it would be particularly worth devising and optimizing a selective-differential medium which would facilitate these tasks, especially in light of the fact that their use for industrial purposes was recently recomended by the OIV and that the number of selected strains of this genus is currently very limited. This differential-selective medium could therefore prove very helpful for any organisms which constitute likely candidates for such selection processes.

The selective agent actidione proved effective against most possible competitor yeast species. Benzoic acid stood out from the other selective agents studied and could be successfully used to eliminate the potential false positives observed in this study, due to the particular resistance of the genus Schizosaccharomyces to this compound. High sugar concentrations and the use of acetic acid could constitute further selective factors. The use of malic acid degradation in liquid media stands out as a differential factor which allows detecting the presence of yeasts able to degrade it.

Lastly, we managed to successfully isolate strains of $S$. pombe from theoretically unpasteurised honey and honeycomb from organic bee farms.

\section{References}

[1] S. Benito, F. Palomero, F. Calderón J.A. SuárezLepe, Encyclopedia of Food Microbiology. 3, 365-370 (2014)

[2] S. Benito, F. Palomero, A. Morata, F. Calderón, J.A. Suárez-Lepe. Eur. Food Res. Technol. 236, 29-36 (2013)

[3] S. Benito, F. Palomero, A. Morata, F. Calderón, J.A. Suárez-Lepe. Food Technol. Biotechnol. 52, 376-382 (2014)

[4] S. Benito, F. Palomero, A. Morata, F. Calderón, J.A. Suárez-Lepe. Food Microbiol. 42, 218-224 (2014)

[5] S. Benito, F. Palomero, A. Morata, F. Calderón, J.A. Suárez-Lepe. Af. J. Microbiol. Res. 7(24), 30263036 (2013) 